\title{
Right Ear Mass, Proptosis, and Dysphagia
}

Amin OSM, ${ }^{\text {a Shwani SS }}{ }^{\mathrm{b}}$

${ }^{a}$ Neurologist, Department of Neurology, Sulaimaniya General Teaching Hospital, Sulaimaniya City, Iraq.

${ }^{b}$ Registrar in Neurology, Department of Neurology, Sulaimaniya General Teaching Hospital, Sulaimaniya City, Iraq.

A 32-year-old man presented with a 9-year history of progressive right-sided hearing loss and pulsatile tinnitus. He also admitted to having difficulty swallowing over the last few years. Oesophagogastroscopy however, was normal. You examined the patient (Figures 1 and 2) and detected right-sided proptosis and absence of right pharyngeal pinprick sensation. The tongue deviated to the right on sticking out. Hearing test on this patient revealed mixed conductive and sensorineural deafness. MRI of the brain had also been performed (Figure 3).
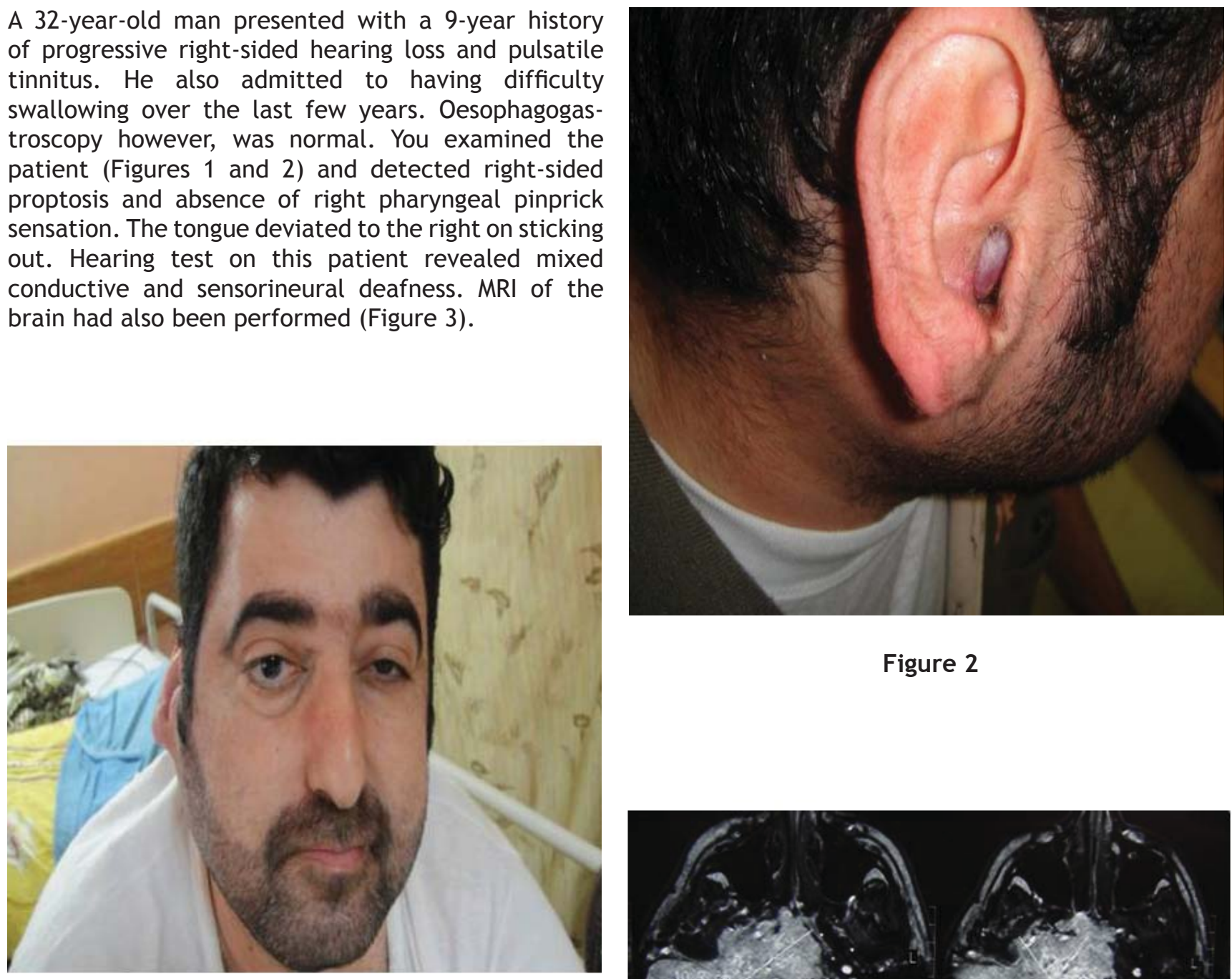

Figure 2

Figure 1

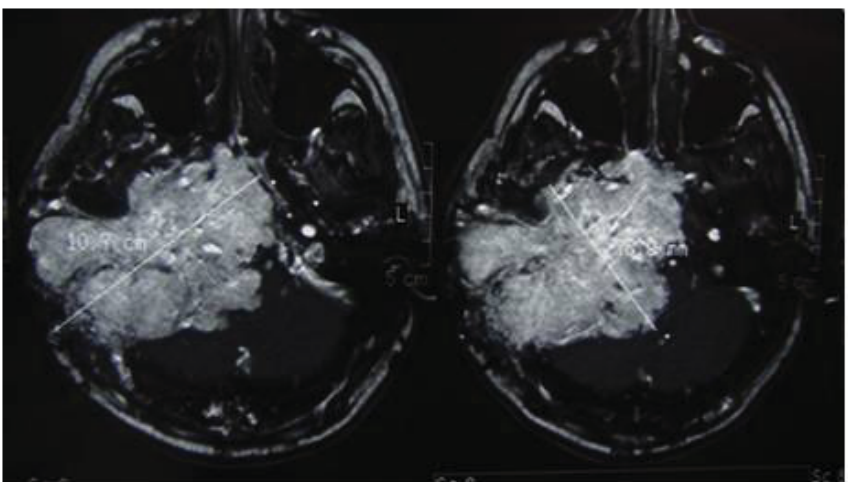

Figure 3 Axial $T_{1}$-weighted image MRI with gadolinium

Corresponding author:

Osama Shukir Muhammad Amin MD, MRCPI, MRCPS(Glasg), FCCP, FACP

Neurologist, Department of Neurology, Sulaimaniya General Teaching Hospital,

Sulaimaniya city, Iraq.

Tel: 009647703515964

E-mail: dr.osama.amin@gmail.com 
QUIZ:

1. What does the man have?

A. Acoustic neuroma.

B. Sphenoid wing meningioma.

C. Chronic otitis media with cholesteotoma.

D. Aberrant intra-petrous internal carotid artery.

E. Glomus jugulare tumour.

Answer: $\mathrm{E}$

2. According to Fisch's classification, his stage is
A. A
B. B
C. $\mathrm{C} 1$
D. C3
E. D2

Answer: $\mathrm{E}$

\section{REFERENCES}

1. Coles MC. Glomus jugulare tumor presentation and mangement: a case study. J Neurosci Nurs 2004; 36(4):221-3, 235.

2. Al-Mefty O, Teixeira A. Complex tumors of the glomus jugulare: criteria, trea ment, and outcome. J Neurosurg 2002; 97(6):1356-66.

3. Ramina R, Maniglia JJ, Fernandes YB, et al. Tumors of the jugular foramen: diagnosis and management. Neurosurgery 2005; 57(1 Suppl):59-68.

\section{DISCUSSION}

The constellation of several years' history of auditory symptoms, right external ear "vascularlooking mass," and the lower cranial nerve involvement (loss of pharyngeal sensation, dysphagia and tongue paralysis) only fits the diagnosis of glomus jugulare tumour. ${ }^{1}$ These tumours are rare, highly vascular, and benign but locally invasive. The clinical presentation relies on the mass effect of the tumour on the lower cranial nerves and brainstem; some tumours may also secrete a variety of hormones, e.g. catecholamines. They are more common in females between the ages of 40 to 70 years and are also more common on the left side; however, our patient is a young male and the tumour is right-sided. They are very slowly growing and the resulting symptoms are minimal and very insidious; an average delay of 6 to 15 years may precede the final diagnosis. The MRI image shows an extensive intracranial extension and according to Fisch's classification, this is the $D_{2}$ stage (tumour with intracranial extension greater than $2 \mathrm{~cm}$ ). The bluish-red polyp (Figure 2) at the right external ear canal in fact lies behind the tympanic membrane and is the iceberg of the tumour. The proptosis implies that the tumour has reached the anterior cranial fossa. Surgical removal is the mainstay of treatment and is variably combined with pre- and post-operative immobilization and radiotherapy. ${ }^{2,3}$ However, the treatment of Fisch's stage $D_{2}$ is controversial. 